\title{
Adsorption and biological decolourization of azo dye Reactive Red 2 in semicontinuous anaerobic reactors
}

\author{
Robert Maas ${ }^{a, b}$, Sanjeev Chaudhari ${ }^{a, *}$ \\ ${ }^{\text {a }}$ Centre for Environmental Science and Engineering, Indian Institute of Technology Bombay, Powai, Mumbai 400 076, India \\ b Institut fur Verfahrenstechnik und umwelttechnik, Technische Universitat Dresden, 01062 Dresden, Germany
}

\begin{abstract}
The microbial decolourization of Reactive Red 2 (RR2) dye has been studied under anaerobic conditions. Three semicontinuous bioreactors were operated with dye concentrations-R1 (control: $\left.0 \mathrm{mg} \mathrm{RR} 2 \mathrm{1}^{-1}\right)$, R2 (100 mg RR2 $1^{-1}$ ) and R3 (200 mg RR2 $\left.1^{-1}\right)$. The parameters monitored were, oxidation-reduction potential (ORP), methane production, colour and chemical oxygen demand (COD) removal during the feeding cycles. The oxidation-reduction potential values for the first few days were above $-150 \mathrm{mV}$, which later on decreased to less than $-275 \mathrm{mV}$ in all the reactors. Colour removal during the first few days of operation was due to adsorption of dye on to anaerobic biomass. However, under steady state conditions, colour removal was above $76 \%$ for both the dye containing reactors and it was due to biologically mediated degradation. Methane production and chemical oxygen demand removal in the control and dye containing reactors were almost the same. Integrated analysis of the monitored parameters indicated that, the primary mechanism of colour removal was adsorption of RR2 on to anaerobic biomass and subsequent degradation. Decolourization rates were found to be first order with respect to dye concentration, although an increase in the influent dye concentration resulted in a decrease in the rate from $0.0074\left(\mathrm{~g}\right.$ volatile suspended solid, VSS) ${ }^{-1} \mathrm{~h}^{-1}\left(100 \mathrm{mg}^{-}\right.$ $\left.\mathrm{RR} 2 \mathrm{1}^{-1}\right)$ to $0.0039(\mathrm{~g} \mathrm{VSS})^{-1} \mathrm{~h}^{-1}\left(200 \mathrm{mg} \mathrm{RR} 2 \mathrm{l}^{-1}\right)$. Based on total methane production no inhibition effect of dyes was observed but total methanogenic activity (TMA) results exhibited inhibition of methanogenesis.
\end{abstract}

Keywords: Azo dye; Adsorption; Degradation; Redox potential; Methanogenic activity

\section{Introduction}

Textile industry wastewater due to the presence of dyes is difficult to treat by traditional wastewater treatment technology. It is estimated that $280,000 \mathrm{t}$ of textile dyes are discharged every year worldwide. Degradation of dyes, especially azo dyes which contribute to about $70 \%$ of all used dyes, is difficult due to their complex structure and synthetic nature [1]. Not only aesthetic problems occur due to dyes, but also biotoxicity and the possible mutagenic and carcinogenic effects of azo dyes have been reported [2]. The colour of dye affects photosynthetic activity in the water body. Further, the released dyes on degradation form toxic amines in sediments [3]. Although some of the dyes are adsorbed on to aerobic sludge in wastewater treatment plants the applied aerobic microbial process cannot readily remove it from wastewater [4]. Additionally the dye reduces the treatment efficiency in these plants [5], which may lead to a collapse of the biological treatment facility. Therefore physico-chemical or physical methods have been investigated to overcome the aforementioned problems. The physico-chemical methods have the limitations of high operational costs and generate large quantity of sludge for disposal. Biological treatment of dyes seems to be a cost effective alternative to the physico-chemical methods. While azo dyes and especially reactive azo dyes are not degradable aerobically, decolourization of azo dyes can be achieved under methanogenic conditions [6,7]. The reductive cleavage of the azo bond of the dyes was investigated under the reducing atmosphere in anaerobic reactors and batch assays. The products basically aromatic amines were found to be more toxic than the actual dyes [1,7]. Therefore further treatment of the effluent is necessary.

Reactive azo dye Reactive Red 2 (RR2) was chosen for this study, because it is widely used for dyeing cellulosic fibres. Only $60-70 \%$ of the reactive dye reacts with the fibre 
during the dyeing process, the remainder is hydrolyzed and is released in to the environment. Beydilli et al. [8] studied the biological decolourization of RR2 under aerobic, anoxic and methanogenic conditions using batch reactors. The dye was not decolourized under aerobic conditions but $92 \%$ decolourization was obtained under anaerobic conditions.

Most of the earlier studies on anaerobic decolourization have focussed on a few significant parameters, such as, colour and chemical oxygen demand (COD) reduction or colour removal and methane production and their significance and correlation is not clear. There is a need to examine the underlying process of anaerobic decolourization. Therefore in this work various significant parameters have been monitored and their correlation is studied. Further, most of the reported kinetic studies on anaerobic biological decolourization used unacclimatized [8] or improperly acclimatized sludge. Thereby adsorption and biologically mediated degradation phenomenon would occur simultaneously and may lead to erroneous estimation of decolourization kinetic constant values. Therefore in this study the variation of all parameters was studied during the start-up phase and when the quasi-steady state conditions were achieved and also it was ascertained that decolourization was occurring due to biologically mediated degradation, then only kinetic studies were conducted. Beydilli et al. [9] and Carliell et al. [6] assessed the toxicity of dyes on the anaerobic biomass, using a maximum rate ratio (MRR) method as suggested by Owen et al. [10]. However, in the present study a comparison between MRR and total methanogenic activity (TMA) test [11] has been done to determine the toxicity of dye on to the biomass.

\section{Materials and methods}

Commercial grade dye RR2 was obtained as water-soluble powder from the local market and used for the study without any further purification. The chemical structure of the dye is shown in Fig. 1.

\subsection{Inoculum}

The anaerobic sludge obtained from a full-scale Upflow Anaerobic Sludge Blanket Reactor (UASB) treating dairy wastewater (Mahananda Dairy, Goregaon, Mumbai, India)

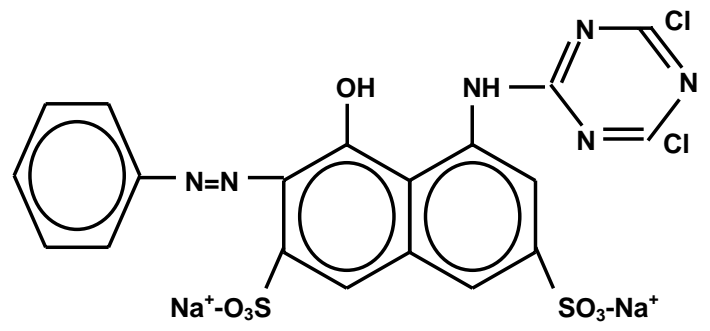

Fig. 1. Chemical structure of Reactive Red 2. was used as an inoculum for the semicontinuous (batch-fed) reactors. After 3 days of storing at room temperature to reduce the organic matter from the dairy process the total suspended solids (TSS) and the volatile suspended solids (VSS) were measured. The sludge was flocculent in nature and contained an initial TSS and VSS of 20.2 and $12.5 \mathrm{~g} \mathrm{l}^{-1}$, respectively. All the bioreactors were seeded with same amount of sludge so as to obtain an initial VSS concentration of $4.4 \mathrm{gl}^{-1}$ as indicated in Table 1 .

\subsection{Feed wastewater}

The feed wastewater was prepared by simulating dye bath effluent. It was prepared as described by Willetts et al. [12]. Stock starch solution $\left(18.7 \mathrm{~g} \mathrm{l}^{-1}\right)$ was prepared by heating for $2 \mathrm{~h}$ at $100^{\circ} \mathrm{C}$. To this solution $28.05 \mathrm{~g}$ sodium bicarbonate was added. The stock dye solution $\left(10 \mathrm{gl}^{-1}\right)$ was prepared by adjusting the $\mathrm{pH}$ of solution to 11 using $0.5 \mathrm{M} \mathrm{NaOH}$ and then heating the solution at $80^{\circ} \mathrm{C}$ for $2 \mathrm{~h}$. The influent feed mainly contained in $\mathrm{gl}^{-1}$ : starch, $1.87 ; \mathrm{NaHCO}_{3}, 2.805$; $\mathrm{NH}_{4} \mathrm{Cl}, 0.58 ; \mathrm{KH}_{2} \mathrm{PO}_{4}, 0.23$. The trace element solution $3 \mathrm{mll}^{-1}$ was added to the feed wastewater, consisting of the following chemicals in $\mathrm{gl}^{-1}: \mathrm{H}_{3} \mathrm{BO}_{3}, 0.05 ; \mathrm{FeCl}_{3}, 2.00$; $\mathrm{MnSO}_{4}, 0.5 ; \mathrm{CuCl}_{2} \cdot 2 \mathrm{H}_{2} \mathrm{O}, 0.03 ;\left(\mathrm{NH}_{4}\right)_{6} \mathrm{Mo}_{7} \cdot 4 \mathrm{H}_{2} \mathrm{O}, 0.05$; $\mathrm{AlCl}_{3} \cdot 6 \mathrm{H}_{2} \mathrm{O}, 0.05 ; \mathrm{CoCl}_{2} \cdot 6 \mathrm{H}_{2} \mathrm{O}, 2.00 ; \mathrm{MnCl}_{2}, 0.25 ; \mathrm{MgCl}_{2}$, 1.00; EDTA, 0.05; $\mathrm{NiCl}_{2} \cdot 6 \mathrm{H}_{2} \mathrm{O}, 0.25$; Yeast extract, 1.0 ; concentrated $\mathrm{HCl}, 1 \mathrm{ml}$.

\subsection{Experimental set-up and reactor schedule}

The experiments were carried out in dark brown glass bottles to avoid photocatalytic degradation of the dyes due to photo oxidation processes. The gases produced were passed through a $\mathrm{NaOH}$ solution. Only methane passed through and both carbon dioxide and hydrogen sulphide were trapped. The methane displaced $\mathrm{NaOH}$ solution from the gas trap and the volume of displaced solution was equivalent to the volume of methane. The produced methane was measured after 24 and $48 \mathrm{~h}$. The experimental set-up is shown in Fig. 2.

The bioreactors were operated under different aqueous phase conditions as mentioned in Table 1 . The control reactor contained only starch, nutrients and trace elements. The

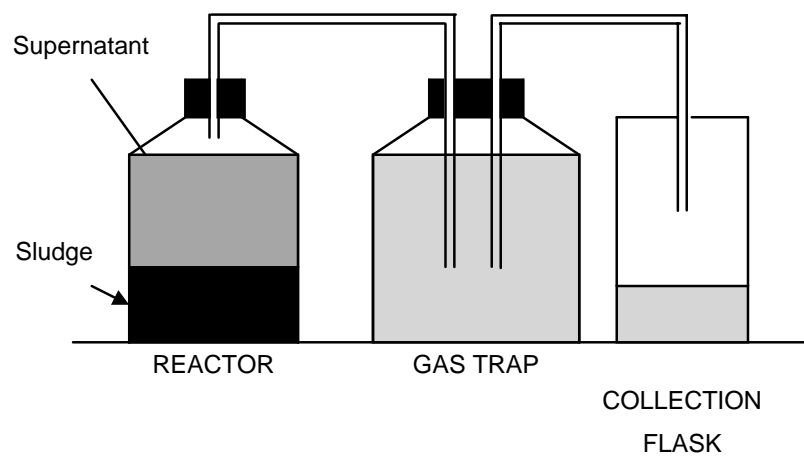

Fig. 2. Schematic of the experimental set-up. 
Table 1

Summary of experimental conditions employed

\begin{tabular}{lll}
\hline Reactor & Initial sludge concentration $\left(\mathrm{g} \mathrm{VSS} 1^{-1}\right)$ & Substrate type \\
\hline R1 control & 4.4 & Starch + nutrients \\
R2 & 4.4 & Starch + nutrients + dye \\
R3 & 4.4 & Starch + nutrients + dye \\
\hline
\end{tabular}

purpose of the control reactor was to delineate the possible toxic/inhibitory effects of the dye on the performance of bioreactor. Reactor 2 (R2) had dye RR2 concentration of $100 \mathrm{mg} \mathrm{l}^{-1}$ and the reactor 3 (R3) had dye concentration of $200 \mathrm{mg}^{-1}$.

The reactor performance was investigated for a period of 27 days. The cycle time was $48 \mathrm{~h}$ for every decanting and refilling process. Initially the reactors were fed for two cycles with the nutrient stock and trace element mixtures and the hydrolyzed starch solution to acclimatize the biomass. On the fourth day the dye was added to R2 and R3.

Each cycle, i.e. every $48 \mathrm{~h} 500 \mathrm{ml}$ of the supernatant was taken out from the reactor bottles and replaced with $500 \mathrm{ml}$ of feed wastewater, which is equivalent to a hydraulic retention time of $96 \mathrm{~h}$. The supernatant served as a sample of the effluent.

All experiments were carried out under sub-mesophilic conditions with temperature in the range $27-29^{\circ} \mathrm{C}$. Total methanogenic activity was measured on the 21 st day and kinetic studies were performed after the 27th day. After the kinetic study, VSS concentration in the bioreactors was measured and used for computation of the decolourization rate constant.

\subsubsection{Total methanogenic activity}

To assess the inhibition/toxicity of dyes on anaerobic biological activity, the method of Owen et al. [10] has been widely used which uses the concept of maximum rate ratio. However, another method based on maximum methanogenic activity (MMA) has been suggested by Soto et al. [11], which indicates the activity for a specific category of biomass (e.g. volatile fatty acid (VFA) utilizing bacteria). The method used in the present study is a modification of the method suggested by Soto et al. [11]. The total methanogenic activity has been estimated which takes into account methanogenic (acetoclastic and hydrogenotrophic) activity of the biomass. The methane produced was measured at regular interval. The slope of methane production of the first $4 \mathrm{~h}$ was taken to compute the TMA of the reactors. TMA is expressed as ( $\left.\mathrm{g} \mathrm{CH}_{4}-\mathrm{COD}\right)\left(\mathrm{g} \mathrm{VSS}^{-1}\right.$ per day.

\subsection{Analyses}

Total alkalinity, COD by closed reflux and titration, total solids (TS), mixed liquor volatile suspended solids (MLVSS) were measured according to the procedure outlined in Standard Methods [13]. Spectrophotometric measurements were carried out at the wavelength of maximum absorbance $\left(\lambda_{\max }\right.$ : $534.2 \mathrm{~nm}$ ) to estimate the dye concentration. The dye was quantified using standard curves of absorbance versus concentration. The amount of dye removed could then be calculated by the difference between the added dye and dye remaining in solution. Absorbance was measured with a Shimadzu UV-Vis Spectrophotometer, Model UV-260. pH was measured using a digital $\mathrm{pH}$ meter (Control Dynamics, India). The oxidation-reduction or redox potential (ORP) was measured with an Orion model 420A pH meter and the Orion platinum redox Electrode, Model 96-78-00 filled with an $\mathrm{Ag} / \mathrm{AgCl}$ reference solution. Measurements were taken always at the same depth below the liquid's surface, because an influence of the measurement height on the ORP was observed by Bromley-Challenor et al. [14].

\section{Results and discussion}

The performance of reactors was studied for 27 days. The quasi-steady state of the reactors was assumed to be achieved when the parameters redox potential of bulk liquid phase in the reactor, $\mathrm{pH}$, methane production, and COD removal were similar for three consecutive feeding cycles. This approach differs from that of other authors where COD removal efficiency is considered as the sole parameter, which must be stable to assume having reached steady state [15]. It is felt that all these parameters are interrelated and affect the performance of anaerobic reactors. Hence a stable value of the aforementioned parameters indicate quasi-steady state conditions in the bioreactor. The control reactor, which was only fed with starch as the sole organic carbon source, nutrients and trace element solutions served as a basis for comparing microbial activity with no toxic effect. The $\mathrm{pH}$ of the reactors was low initially and after 8 days of reactor operation the $\mathrm{pH}$ of the effluent stabilized in a range between 7.2 and 7.5. The low effluent $\mathrm{pH}$ during the initial phase might be due to formation of acids (VFA) more than the consumption by the methanogenic bacteria which has been widely reported.

\subsection{Redox potential variation}

Redox potential has an influence on the decolourization rate under methanogenic conditions as reported in the batch assays $[6,14]$. However, monitoring of ORP in continuous or semicontinuous systems is scantily reported. The influence 

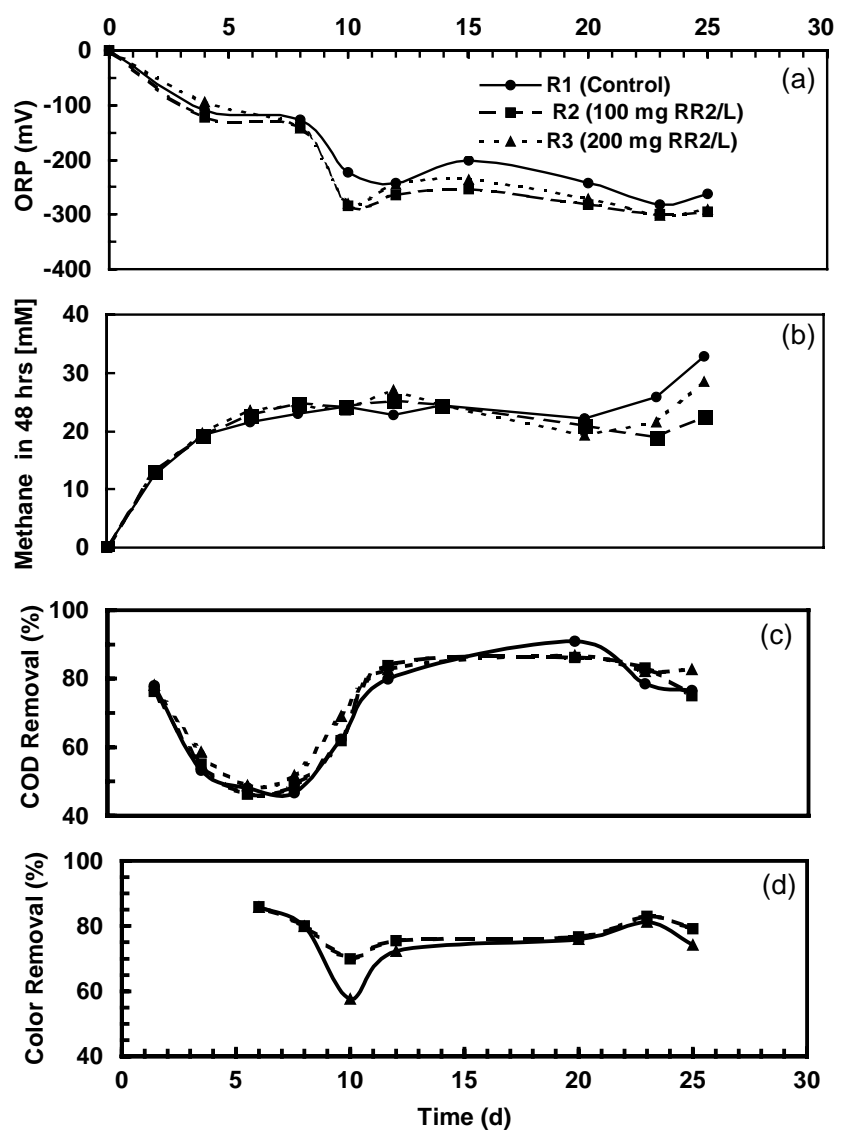

Fig. 3. Temporal variation of parameters in reactors.

of ORP on decolourization has been reported by Carliell et al. [6] in batch anaerobic reactors. Fig. 3a presents the variation of redox potential in the reactors operated. It is apparent from the figure that during an initial phase of up to 8 days ORP in the bioreactors were in the range of -100 to $-130 \mathrm{mV}$, which on 10th day reduced to much lower values. The ORP values in the dye containing reactors $\mathrm{R} 2$ and R3 attained a stable value of about $-290 \mathrm{mV}$. The ORP of $-290 \mathrm{mV}$ in the bulk liquid indicate that anaerobic conditions prevailed in the reactors from 10th day onwards, and therefore it is less likely that anaerobic decolourization of dyes would occur before 10th day of operation. The control reactor attained stable ORP after 10 days and the ORP in the dye containing reactors remained at lower levels compared to the control reactor. One possible explanation for this phenomenon is that sulphonate moiety of RR2 dye might be used by sulphate reducing bacteria (SRB) as electron acceptor. Sulphide possibly produced in the reduction of the sulphonate moiety would reduce the bulk phase redox potential. Lie et al. [16] reported that a strain of Desulfovibrio utilized some sulphonates as electron acceptor in place of sulphates. Hence it is likely that the dye degradation products such as sulphides might be the cause for the lower ORP in dye containing reactors than the control reactor.

\subsection{Methane production}

Methane production was monitored to assess the toxic effect of dyes on the anaerobic process. The anaerobic process is a multi-step process, methane production occurs in the final step and methane production has been widely used to assess toxicity. Fig. $3 \mathrm{~b}$ presents methane production in the bioreactors. It is evident from the figure that methane production increased up to the 10th day and then stabilised at around $24 \mathrm{mM}(600 \mathrm{ml})$. Methane production in all the three reactors is nearly the same in $48 \mathrm{~h}$. Therefore if total methane produced in $48 \mathrm{~h}$ is considered than it is apparent that RR2 concentration up to $200 \mathrm{mg} \mathrm{l}^{-1}$ did not inhibit the anaerobic process. Beydilli et al. [8] in batch reactor with RR2 concentration of $300 \mathrm{mg} \mathrm{l}^{-1}$ observed slightly more methane and total gas production than the control reactor, and concluded that RR2 concentration up to $300 \mathrm{mg}^{-1}$ did not inhibit the biodegradation of the organic feed and its conversion to methane.

\subsection{COD removal}

Fig. $3 \mathrm{c}$ presents the performance of semicontinuous reactors for COD removal. After high values of COD removal during the first few days the removal decreased to $50 \%$ on the 6th day, which later on increased to $80 \%$. It is likely that during the first few days sorption of starch (substrate) occurred on to the biomass and thereby good COD removal was observed at the beginning of the reactor operation. The biodegradation of substrate might not have occurred as the methane production is less up to sixth day. Later the sorption sites on the biomass for starch were exhausted and therefore the COD removal efficiency decreased. Then as the biomass became acclimatized to the substrate, the COD removal efficiency increased again and remained at around $80 \%$ until the end of reactor operation. The COD removal in all three reactors was nearly the same and no significant effect of dye on COD removal was observed. The observed adsorption of starch onto sludge is in agreement with the reported literature. Mino et al. [17] observed that the hydrolysis rate of starch followed surface limited adsorption reaction kinetics and suggested that adsorption of starch occurred on the biological floc before it was hydrolyzed. The property of biomass to adsorb substrate is also utilized in the contact stabilization activated sludge process [18].

\subsection{Colour removal}

Fig. 3d presents the variation of colour removal with time. On the fourth day the dye solution was fed to the reactors. Colour removal on sixth day was $86 \%$ in both the dye containing reactors, which on the 10th day reduced to $57 \%$ in $\mathrm{R} 3$ and to $70 \%$ in $\mathrm{R} 2$. The observed reduction in colour removal could be due to adsorption of the dye onto the biomass as stated by $\mathrm{Hu}$ [19]. It is likely that on the first day of dye addition (i.e. fourth day), available adsorption sites for 
dye on biomass were abundant and therefore colour removal was quite high. On subsequent addition of dye, colour removal decreased due to less available adsorption sites. This is also supported by the higher bulk phase ORP values and less methane production on fourth and sixth day, which indicate anaerobic conditions did not prevail in the reactor and therefore reductive degradation of dye is unlikely to occur. Further, the UV-Vis spectra of the effluent also indicated that dye removal in the initial days was due to adsorption (UV-Vis absorbance spectra not shown). Similar observations have been made by Aretxaga et al. [20] while conducting experiments with live and dead biomass pellets of Trametes versicolor. It was observed that adsorption played an important role and accounted for around $80 \%$ of colour elimination.

Colour removal in the reactors was lowest on the 10th day and after which the colour removal efficiency increased. The stable value of colour removal in R2 and R3 was 78 and $76 \%$, respectively. During the steady state phase of the reactors, which showed almost stable decolourization efficiency, the dye degradation was biologically mediated. This was evident as the absorbance at the maximum wavelength for effluent of R2 and R3 decreased in the visible range and increased at the same time in the UV range. The absorbance spectra of the influent and effluent for R2 $\left(100 \mathrm{mg} \mathrm{l}^{-1}\right.$ dye reactor) are shown in Fig. 4. The spectra of the effluent clearly showed a shift of the peaks towards the UV range. Beydilli et al. [8] analyzed the degradation products of RR2 by HPLC and UV-Vis spectra and observed the presence of aniline and aminohydroxynaphthalene derivatives in the effluent. Further, Feng et al. [21] also have reported the formation of degradation products of RR2 and the shift of the peaks to a new wavelength with a value of $245 \mathrm{~nm}$ in the

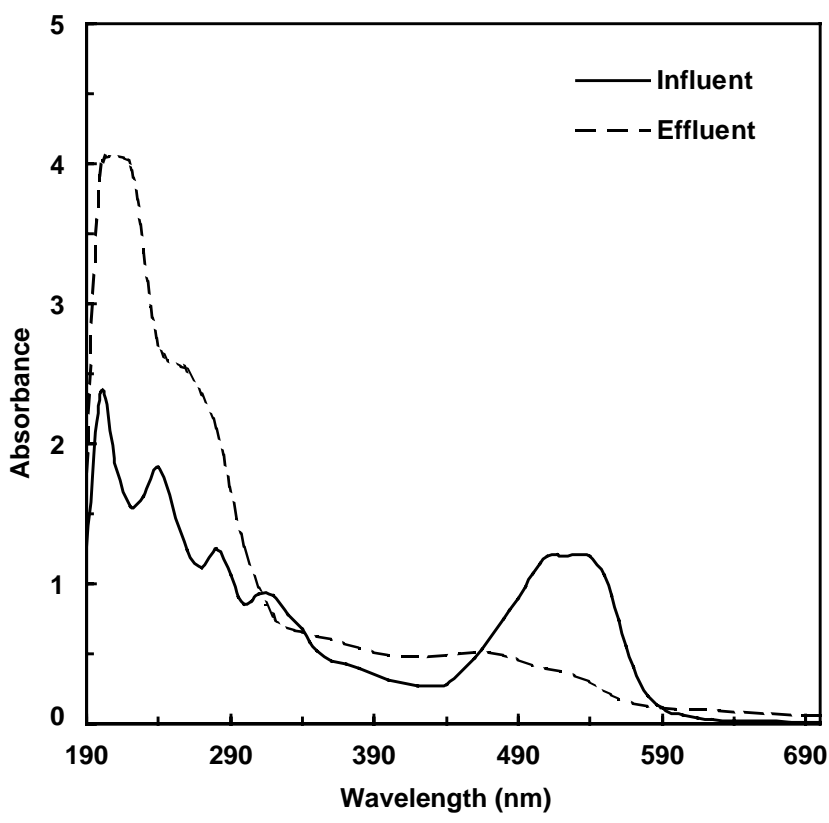

Fig. 4. Absorbance spectra for Reactor 2-100 mg RR $21^{-1}$. effluent spectra. Although they used iron powder as a reducing agent their effluent (liquid after iron powder treatment) absorbance spectra was found to be similar to the spectra of the effluent from R2 and R3. This also illustrates that the decolourization of the dye was not due to adsorption onto the biomass under steady state conditions but due to degradation due the prevailing reducing environment inside the reactor, which can also be simulated with iron powder.

If the parameters ORP, methane production, COD removal and colour removal are considered together, then it appears that the primary mechanism of colour removal is, first adsorption of dye on the biomass followed by biologically mediated degradation.

\subsection{Kinetic studies}

Kinetic studies were undertaken to observe the factors affecting the rate of decolourization. The study was carried out in the steady state phase of the reactors after the 27 th day. The results obtained are presented in Fig. 5. It is apparent from the figure that up to $3 \mathrm{~h}$ the ORP values were high and colour removal did not occur. This indicates that colour removal under anaerobic conditions started only when the bulk liquid phase ORP was in a range between -150 and $-200 \mathrm{mV}$. Similar observations have been reported by Bromley-Challenor et al. [14]. After the ORP decreased below this value a sudden decolourization occurred suggesting that the influence of the ORP is very important for the kinetics. Beydilli et al. [8] while conducting batch biodegradation test observed that RR2 did not decolourize under aerobic conditions, whereas under anaerobic conditions decolourization occurred. The decolourization of RR2 followed first order kinetics and a higher dye concentration of RR2 showed a higher $k$-value (lesser decolourization rate) as was found by Carliell et al. [6]. The $k$-value

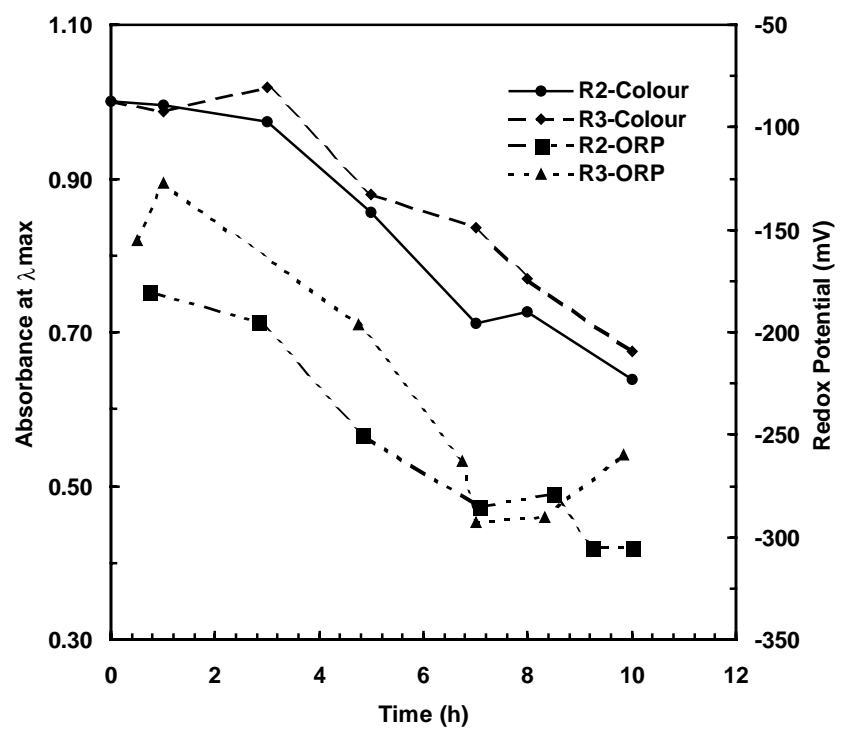

Fig. 5. Colour and redox potential variation during kinetic studies. 


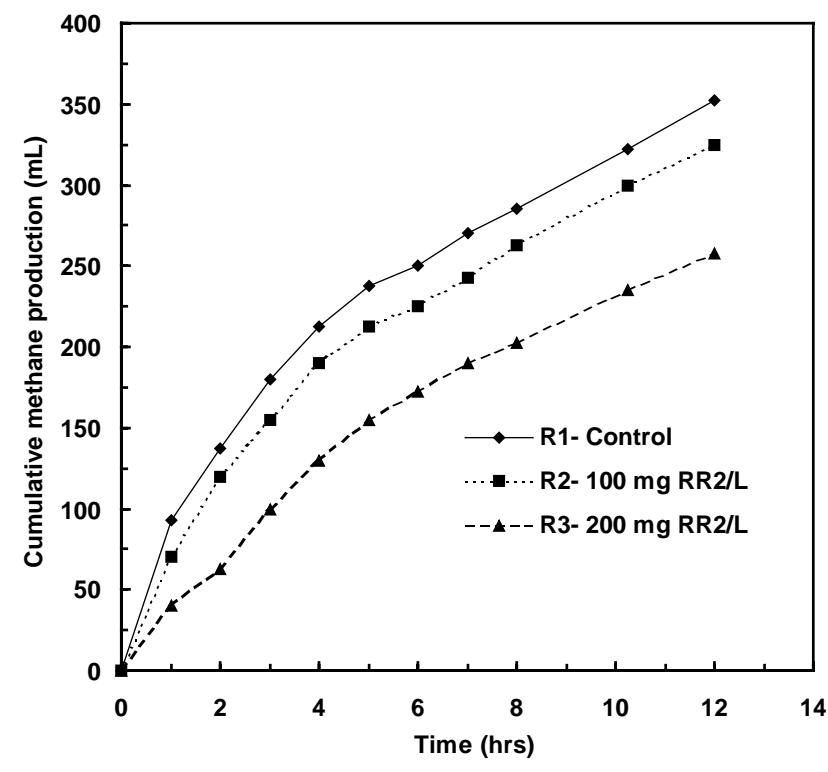

Fig. 6. Methane production profile during total methanogenic activity test.

for RR2 with $100 \mathrm{mgl}^{-1}$ (R2) was found to be -0.0074 $\left(\mathrm{g} \mathrm{VSS}^{-1} \mathrm{~h}^{-1}\right.$ and for RR2 with $200 \mathrm{mgl}^{-1}$ (R3) it was $-0.0039(\mathrm{~g} \mathrm{VSS})^{-1} \mathrm{~h}^{-1}$. With aqueous phase conditions, such as, ORP, $\mathrm{pH}$ and methane produced in $48 \mathrm{~h}$, being the same in $\mathrm{R} 2$ and $\mathrm{R} 3$. The lesser decolourization rate $(k)$ in $\mathrm{R} 3$ than in R2 suggests that the rate of production of reducing equivalents in the anaerobic reactor was the rate-limiting factor for RR 2 concentration of $200 \mathrm{mg} \mathrm{l}^{-1}$. The earlier studies on dye decolourization did not consider the biomass (anaerobic sludge) concentration for computing the rate constant. However, to compare the $k$-value obtained in this study the values reported by Zee et al. [22] have been computed considering the biomass concentration and they are computed to be $0.0086(\mathrm{~g} \mathrm{VSS})^{-1} \mathrm{~h}^{-1}$ at dye concentration of approximately $0.3 \mathrm{mM}$.

\subsection{Total methanogenic activity}

Methane production in $48 \mathrm{~h}$ in $\mathrm{R} 1, \mathrm{R} 2$ and $\mathrm{R} 3$ were almost same as evident from Fig. 3b. Hence, MRR (methane produced in the dye spiked reactor/methane produced in control) would be 1 , which indicates no toxic/inhibitory effect of the dye on the anaerobic process. Beydilli et al. [8] used the total gas and total methane parameter to examine the inhibitory effect of the dye or salts on the methanogenic bacteria. While Soto et al. [11] described a method to assess inhibition effects by computing the maximum methanogenic activity of anaerobic sludge. The method is based on the maximum rate of methane production per unit weight of biomass under unlimited substrate condition. The more active the methanogenic bacteria in the sludge more methane should be produced in the first few hours. Fig. 6 presents the methane produced with time in the different bioreactors. It is apparent from the figure that the rate of methane production is higher in the control reactor than the dye containing reactors. It is also evident that rate of methane production decreases with increase in dye concentration. The maximum slope is used to determine the total methanogenic activity. The total methanogenic activity in the reactors has been worked out to be, for the control reactor (R1): 0.64 (g CH 4 -COD) $\left(\mathrm{g} \mathrm{VSS}^{-1}\right.$ per day; $100 \mathrm{mgl}^{-1}$ (R2) dye reactor: $0.57\left(\mathrm{~g} \mathrm{CH}_{4}-\mathrm{COD}\right)(\mathrm{g} \mathrm{VSS})^{-1}$ per day; and for $200 \mathrm{mg} \mathrm{l}^{-1}$ (R3) dye reactor: $0.45\left(\mathrm{~g} \mathrm{CH}_{4}-\mathrm{COD}\right)(\mathrm{g} \mathrm{VSS})^{-1}$ per day. Therefore based on the TMA values the inhibitory effect of dye on the anaerobic process is apparent.

\section{Conclusions}

This work studied the decolourization of azo dye RR2 in semicontinuous anaerobic reactors. After an initial adsorption of dye on the biomass subsequent degradation of dye occurred. The primary mechanism of dye removal appears to be adsorption of dye on biomass followed by biodegradation. Under steady state conditions, the parameters ORP, methane produced, COD and colour removal attained nearly stable values. RR2 decolourization of up to $78 \%$ could be achieved. The kinetic studies showed a first order behaviour for the two dye concentrations evaluated. The decolourization of dyes was initiated only when the bulk phase redox potential attained a value lower than $-150 \mathrm{mV}$. Based on the total methane produced during the feeding cycles, no toxic effect of dyes was observed on methanogenesis. However, based on the TMA estimates the toxicity effect was evident.

\section{References}

[1] Sosath F. Biologisch-chemische Behandlung von Abwässern der Textilveredelung mit ReaKtivfarbstoffen, VDI Fortschrittsberichte, Reihe Umweltverfahrenstechnik 1999;209.

[2] Chang J, Chou C, Lin Y, Lin P, Ho J, Hu TL. Kinetic characteristics of bacterial azo-dye decolorization by pseudomonas luteola. Water Res 2001;35:2841-50.

[3] Chung KT, Fulk GE, Egan M. Reduction of azo dyes in intestinal anerobes. Appl Environ Microbiol 1978;35:558-62.

[4] Brown D, Hitz HR, Schefer L. The assessment of the possible inhibitory effect of dyestuffs on aerobic wastewater bacteria: experience with screening test. Chemosphere 1981;10:245-61.

[5] Meehan C, Banat IM, McMullan G, Nigam P, Smyth F, Marchant R. Decolorization of Remazol Black-B using a thermotolerant yeast Kluyveromyces marxianus IMB3. Environ Int 2000;26:75-9.

[6] Carliell CM, Barclay SJ, Naidoo N, Buckley CA, Muulholland DA, Senior E. Microbial decolourisation of a reactive azo dye under anaerobic conditions. Water SA 1995;21:61-9.

[7] Willetts JRM, Ashbolt NJ. Understanding anaerobic decolourisation of textile dye wastewater: mechanism and kinetics. Water Sci Technol 2000;42:409-15.

[8] Beydilli MI, Pavlostathis SG, Tincher WC. Biological decolorization of azo dye reactive red 2 under various oxidation-reduction conditions. Water Environ Res 2000;72:698-705.

[9] Beydilli MI, Pavlostathis SG, Tincher WC. Decolourization and toxicity screening of selected reactive dyes under methanogenic conditions. Water Sci Technol 1998;38:225-32. 
[10] Owen WF, Stuckey DC, Healy JB, Young LY, McCarty PL. Bioassay for monitoring biochemical methane potential and anaerobic toxicity. Water Res 1979;13:485-92.

[11] Soto M, Mendez R, Lema JM. Methanogenic and non-methanogenic activity tests: Theoretical basis and experimental set up. Water Res 1993;27:1361-76.

[12] Willetts JRM, Ashbolt NJ, Moosbrugger RE, Aslam MR. The use of a thermophilic anaerobic system for pretreatment of textile dye wastewater. Water Sci Technol 2000;42:309-16.

[13] APHA, AWWA, WPCF. Standard Methods for the Examination of Water and Wastewater, 20th ed. Washington, DC: American Public Health Association; 1998

[14] Bromley-Challenor KCA, Knapp JS, Zhang Z, Gray NCC, Hetheridge MJ, Evans MR. Decolorization of an azo dye by unacclimated activated sludge under anaerobic conditions. Water Res 2000;34:44108.

[15] O'Neill C, Hawkes FR, Hawkes DL, Esteves S, Wilcox SJ. Anaerobic-aerobic biotreatment of simulated textile effluent containing varied ratios of starch and azo dye. Water Res 2000;34:235561 .
[16] Lie TJ, Pitta T, Leadbetter ER, Godchaux W, Leadbetter JR. Sulfornates: novel electron acceptors in anaerobic respiration. Arch Microbiol 1996;166:204-10.

[17] Mino T, Pedro DCS, Matsuo T. Estimation of the rate of slowly biodegradable COD (SBCOD) hydrolysis under anaerobic, anoxic and aerobic conditions by experiments using starch as model substrate. Water Sci Technol 1995;31:95-103.

[18] Tchobanoglous T, Burton FL, Stensel HD. Wastewater EngineeringTreatment and Reuse. New Delhi: Tata McGraw-Hill Publishers; 2003.

[19] Hu TL. Sorption of reactive dyes by Aeromonas biomass. Water Sci Technol 1996;26:357-66.

[20] Aretxaga A, Romero S, Sarra M, Vincent T. Adsorption step in the biological degradation of a textile dye. Biotechnol Prog 2001;17:664 8.

[21] Feng W, Nansheng D, Helin H. Degradation mechanism of azo dye C.I. Reactive Red 2 by iron powder reduction and photooxidation in aqueous solutions. Chemosphere 2000;41:1233-8.

[22] Zee FP, Letinga G, Field JA. Azo dye decolourisation by anaerobic granular sludge. Chemosphere 2001;44:1169-76. 